\title{
Bifurcation Phenomena of Voltage Regulated Forward Converter in CCM and DCM Mode
}

\author{
Wei, HU \\ Lab Center \\ Guangzhou University \\ Guangzhou, China \\ pehuwei@gzhu.edu.cn \\ Xinbing, CHEN \\ Lab Center \\ Guangzhou University \\ Guangzhou, China \\ cenpop@gmail.com
}

\author{
Fangying, ZHANG \\ Lab Center \\ Guangzhou University \\ Guangzhou, China \\ zfy@gzhu.edu.cn \\ Xiaoli, LONG \\ Lab Center \\ Guangzhou University \\ Guangzhou, China \\ xllong@gzhu.edu.cn
}

\begin{abstract}
This paper focus on the bifurcation behaviors of voltage regulated forward converter. Meanwhile it builds a mathematical model based on voltage closed-loop control system, and discusses load resistance that makes system produce bifurcation phenomena. The bifurcation mechanism indicates that with the value of load resistance increases, voltage regulated forward converter output voltage operates from stable period-1 state to period doubling bifurcation till intermittency chaos. When the resistance values continue to increase, locking cycle six and the period doubling bifurcation phenomena emerge again, in the end the output voltage enter into stable one periodic orbit. The chaos phenomenon is stabilized by extra voltage compensation. The simulation result proves that the accuracy of theoretical analysis.
\end{abstract}

Keywords-Forward converter; CCM; DCM; bifurcation; voltage regulate

\section{INTRODUCTION}

Recently, nonlinear behavior of power electronic converters is studied and applied widely [1,2]. Especially a lot of useful research results about non isolated converter bifurcation and chaos in DC-DC converter are obtained [37].

But topology structure of isolated converter is more complicated than non isolated converter, as it adds a power converter. Its nonlinear behavior is researched rarely. The document [9] studied flyback converter quasi-period and Hopf bifurcation phenomena; the document [10] studied period doubling bifurcation mechanism in flyback converter in DCM; the document $[11,12]$ studied unstable behavior in Forward converter in DCM. But these documents only analyzed the unstable behavior in DC-DC converter in CCM or DCM, in the whole work range the bifurcation behavior in system was not analyzed. As a result, the applications of Forward converter in industry are restricted.

Based on the above analysis, this paper studied that when the load resistance values continued to increase, the converter is from CCM mode to DCM mode and output voltage and the inductor current enter into bifurcation and chaos state from stable one periodic state, come back to stable period-1 orbit in the end. This paper discussed the path that the system produced instability behavior, and provided phase diagram of bifurcation and intermittent chaos.

The second section introduced operational principle and mathematical model of Forward converter. The third section analyzed bifurcation behavior of system and provided PSIM simulation model of converter and simulation results. The fourth section studied deeply method of stabilization converter. The fifth section is conclusion.

\section{VOLTAGE REgUlated FoRWARd CONVERTER MODEL}

Wherever Times is specified, Times Roman or Times New Roman may be used. If neither is available on your word processor, please use the font closest in appearance to Times. Avoid using bit-mapped fonts if possible. TrueType 1 or Open Type fonts are preferred. Please embed symbol fonts, as well, for math, etc.

The schematic of Forward converter is illustrated in Fig .1. This transformer-isolated converter is based on the buck converter. Its nonpulsating output current, shared with other buck-derived converters, makes the forward converter well suited for applications involving high output currents. The operation modes of the system are shown in Fig .1. a), b), c). a) is S turn-off; b) is S turn-on and inductor charging mode; c) is discontinues conduction mode.

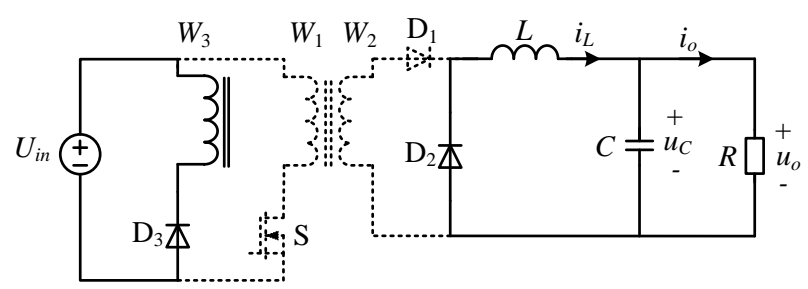

a) S turn-off 


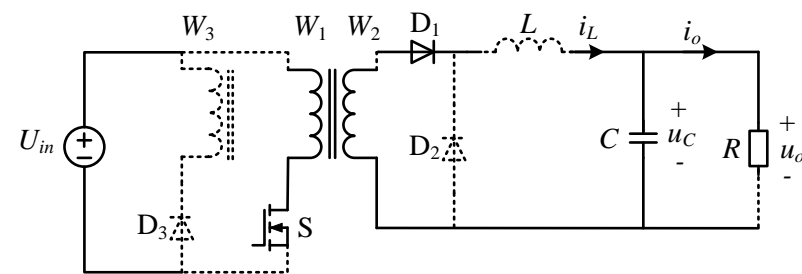

b) S turn-on

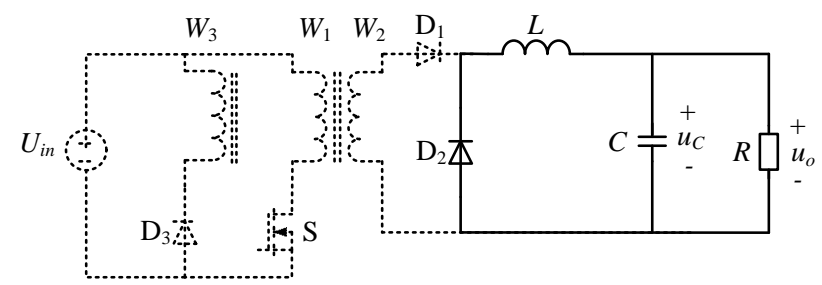

c) DCM mode

Figure 1. Forward converter work mode

Let $W_{1}=W_{3}, \quad W_{1}=K_{12} W_{2}$, and converter simplified model

$$
\begin{aligned}
& U_{s n}=\frac{1}{K_{12}} \frac{1}{1+\eta} U_{i n} \\
& \eta=L_{e} / L_{m}
\end{aligned}
$$

where, $L_{e}$ is leakage inductance of transformer, $L_{m}$ is excitation inductance of the transformer.

The state matrices of the Forward converter are shown at Tab. I.

TABLE I. STATE MATRICES

\begin{tabular}{ll}
\hline$A_{2}(\mathrm{~S}$ off $)$ & $A_{1}(\mathrm{~S}$ on $)$ \\
\hline$\left[\begin{array}{rr}0 & -\frac{1}{L} \\
\frac{1}{C} & -\frac{1}{R C}\end{array}\right]$ & {$\left[\begin{array}{rr}0 & -\frac{1}{L} \\
\frac{1}{C} & -\frac{1}{R C}\end{array}\right]$} \\
$B_{2}(\mathrm{~S}$ off $)$ & $B_{1}(\mathrm{~S}$ on $)$ \\
{$\left[\begin{array}{l}0 \\
0\end{array}\right]$} & {$\left[\begin{array}{c}\frac{U_{\text {in }}}{L} \\
0\end{array}\right]$} \\
\hline
\end{tabular}

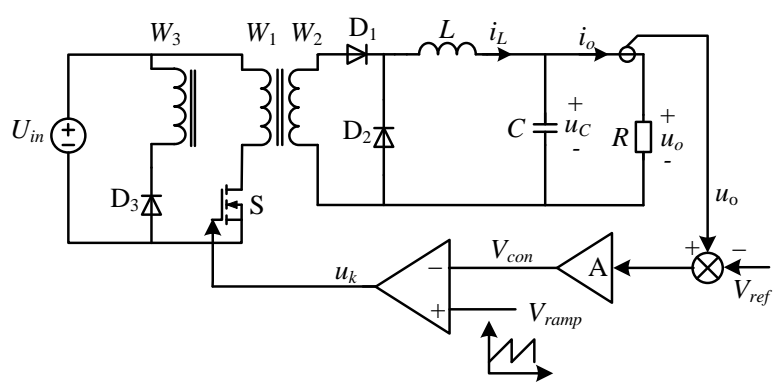

Figure 2. Schematic diagram of voltage controlled Forward converter
The Schematic diagram of voltage controlled Forward converter is shown in Fig .2. Control strategy of the system is shown as:

$$
h: V_{\text {ramp }}-k\left(u_{o}-V_{\text {ref }}\right)=0
$$

At the time instant of $t=0, V_{\text {ramp }}<V_{\text {con }}, \mathrm{S}$ is turn-off and the converter is working in the range of $\left[A_{2}, B_{2}\right]$, the inductor current $i_{L}$ decreases. At the time instant of $t=d T, V_{\text {ramp }} \geq V_{\text {con }}, \mathrm{S}$ is turn-on and the converter is working in the range of $\left[A_{1}, B_{1}\right]$, the inductor current $i_{L}$ increases.

Refer to reference [9], iterative equation of switching point belongs to the voltage controlled Forward converter are as follows

$$
\begin{gathered}
e^{\boldsymbol{A}_{1} d T} \boldsymbol{x}(n T)+\boldsymbol{A}_{1}^{-1}\left(e^{\boldsymbol{A}_{1} d T}-\boldsymbol{I}\right) \boldsymbol{B}_{1} U_{i n}-\boldsymbol{x}(n T+d T)=0, \\
e^{\boldsymbol{A}_{2}(1-d) T} \boldsymbol{x}(n T+d T)+\boldsymbol{A}_{2}^{-1}\left[e^{\boldsymbol{A}_{2}(1-d) T}-\boldsymbol{I}\right] \boldsymbol{B}_{2} U_{i n} \\
-\boldsymbol{x}[(n+1) T]=0
\end{gathered}
$$

where, $d$ is the duty cycle, and $d^{\prime}=1-d$.

Solving the above equations by MATLAB numerically with the Newton-Raphson method, the values of $\boldsymbol{x}$ and duty cycle $d$ can be obtained for the periodic orbit.

Discrete-time model of the closed-loop system is as follows

$$
\begin{array}{r}
\boldsymbol{x}[(n+1) T]=e^{\boldsymbol{A}_{2}(1-d) T}\left[e^{\boldsymbol{A}_{1} d T} \boldsymbol{x}(n T)+\boldsymbol{A}_{1}^{-1}\left(e^{\boldsymbol{A}_{1} d T}-\boldsymbol{I}\right) \boldsymbol{B}_{1} U_{i n}\right] \\
+\boldsymbol{A}_{2}^{-1}\left[e^{\boldsymbol{A}_{2}(1-d) T}-\boldsymbol{I}\right] \boldsymbol{B}_{2} U_{i n}
\end{array}
$$

It is clear that Eq. (6) shows the iteration mathematical model of CCM mode voltage controlled Forward converter. The DCM mode model can be obtained by the same way, which is omitted here.

\section{ANALYSIS OF BIFURCATION BEHAVIORS}

The PSIM simulation model of the voltage controlled Forward converter is shown as Fig .3. In order to facilities the analysis, this paper chose circuit parameters as shown in Tab. II.

When load resistor increased gradually, the system operates from CCM mode to DCM mode. In the process of this, the system is in CCM mode firstly, output voltage and inductor current is from stable one periodic state to period doubling bifurcation and chaos gradually. With load resistor continuing to increase, the system entered into DCM mode, and phase diagram of state variable emerged locking cycle six bifurcation phenomena and period doubling bifurcation, enter into stable one periodic orbit in the end.

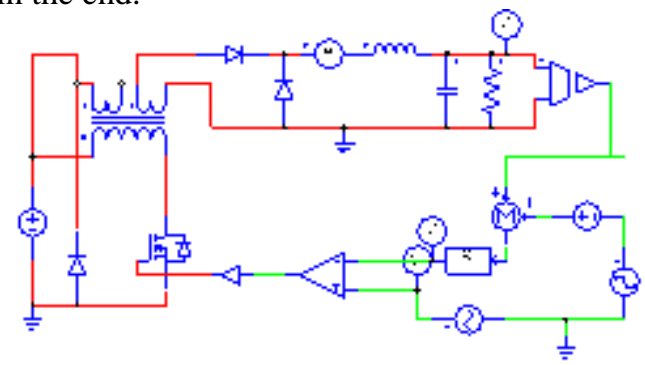

Figure 3. The simulation model of the voltage controlled Forward converter (CCM and DCM) 
TABLE II. CIRCUIT PARAMETER

\begin{tabular}{llll}
\hline parameter & value & parameter & value \\
\hline$U_{\text {in }}$ & $48 \mathrm{~V}$ & $L$ & $1 \mathrm{mH}$ \\
$L_{m}$ & $2 \mathrm{mH}$ & $C$ & $11.5 \mu \mathrm{F}$ \\
$K_{12}$ & 1.8 & $V_{\text {ref }}$ & $20 \mathrm{~V}$ \\
$A$ & 1.4 & $f$ & $5 \mathrm{kHz}$ \\
\hline
\end{tabular}

A. stable period-1 state

When load resistor $R=6 \Omega$, the system is in stable period-1 state,

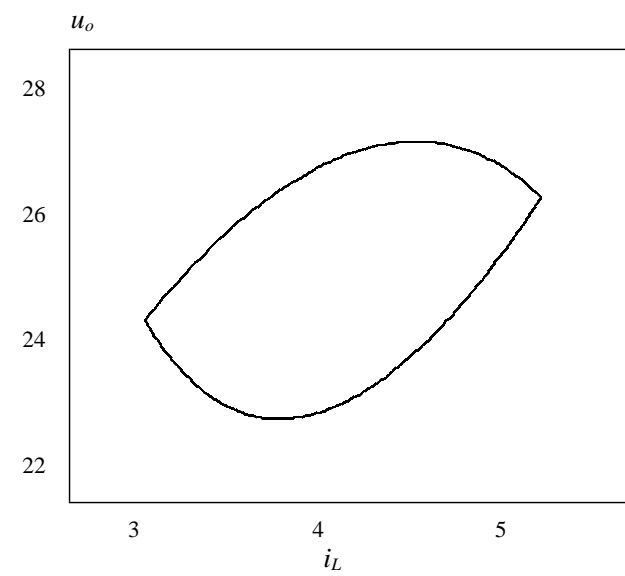

Figure 4. when $R=6 \Omega$, it is one periodic phase diagram

\section{B. period doubling bifurcation}

When load resistor $R=8 \Omega$, the system is in period doubling bifurcation state.

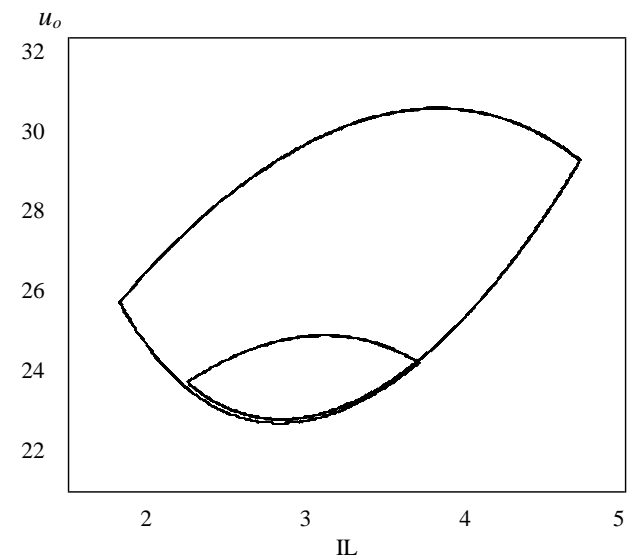

Figure 5. when $R=8 \Omega$, it is period doubling bifurcation phase diagram

\section{C. intermittent chaos state}

When load resistor $R=12.5 \Omega$, the system is in intermittent chaos state

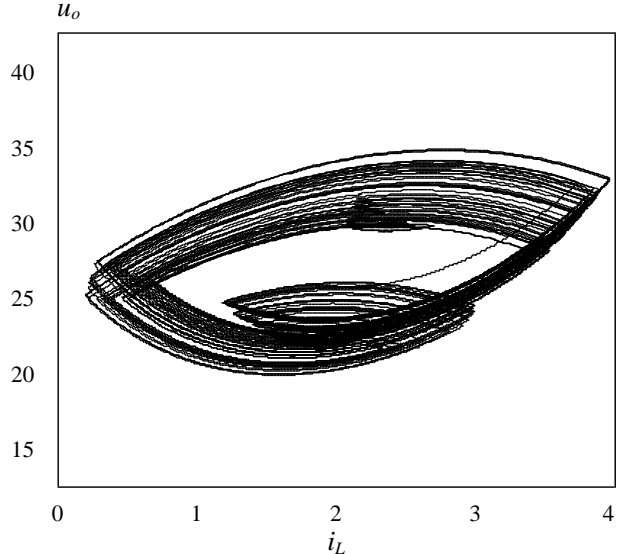

Figure 6. when $R=12.5 \Omega$, it is intermittent chaos phase diagram(CCM mode)

\section{D. locking cycle six}

When load resistor $R=16 \Omega$, the system is in locking cycle six state.

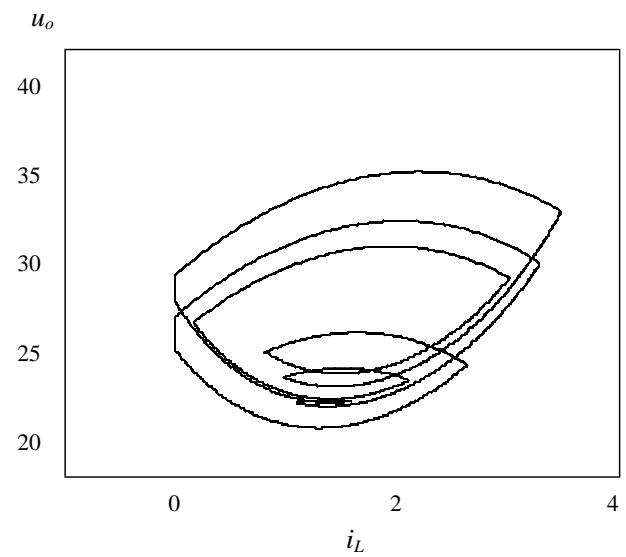

Figure 7. when $R=16 \Omega$, it is in locking cycle six state(CCM and DCM mixed model)

\section{E. period doubling bifurcation}

When load resistor $R=20 \Omega$, the system entered into DCM mode, and was in period doubling bifurcation state.

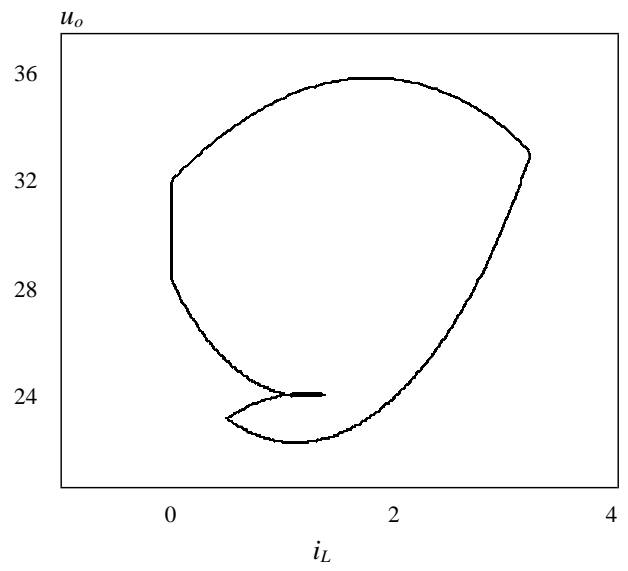

Figure 8 . As $R=20 \Omega$, it is period doubling bifurcation phase diagram 


\section{$F$. stable one periodic state}

When load resistor $R=100 \Omega$, the system is in DCM mode, and is stable period- 1 state.

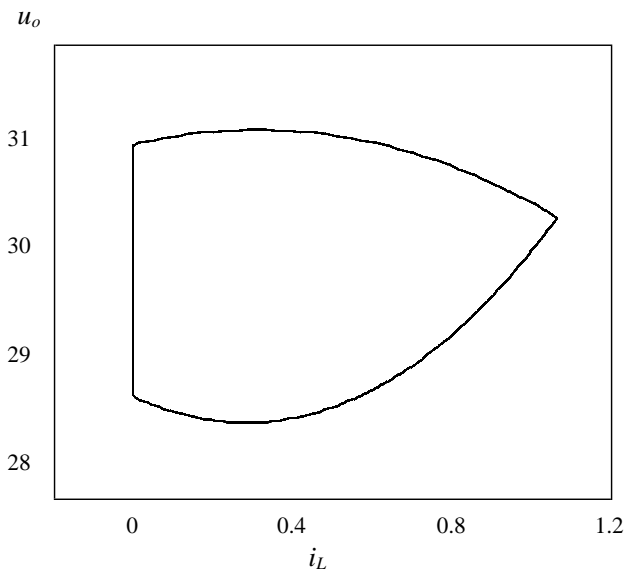

Figure 9. when $R=100 \Omega$, it is one periodic orbit phase diagram

\section{STABILIZATION ABOUT CHAOS BEHAVIOR}

The resonant parametric perturbation method is applied to control the afore-mentioned chaotic system and expand the stability boundary. A sinusoidal signal $U_{e}$ with the same frequency as driving signal $f$ is added on the $U_{r}$. Additive sinusoidal signal $U_{e}$ takes the form $a \sin (2 \pi f t)$.

In order to control chaos phenomena of converter and make the system stabilize stable one periodic state, this section proposed the method that sinusoidal voltage compensation controlled output of the system. When $t=0.18 s$ and $f=5 \mathrm{kHz}$, amplitude voltage $2 \mathrm{~V}$ is added to reference voltage $V_{\text {ref. }}$. The wave form of output voltage is shown as Fig .10. It can be seen from the graph that after at the time of $0.18 \mathrm{~s}$ sinusoidal voltage compensation is added, output voltage that spent 10 periods is controlled to obvious one periodic stable state.

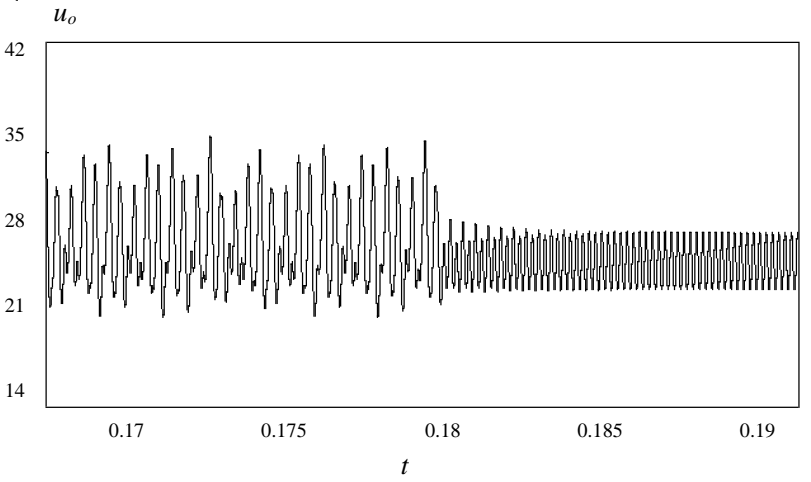

Figure 10. Transient responses of the output voltage based on stabilization control strategy.

\section{CONCLUSIONS}

Operation modes are more complicated than traditional non-isolated converter as voltage regulated forward converter has one transformer, and input and output are isolated. The research results show that with output resistor increasing, voltage regulated forward converter is from CCM mode to DCM mode. In the process of this, the system is going to be stable period-1 state, period doubling bifurcation, intermittent chaos, and then be re entered the locking cycle and period doubling bifurcation state, in the end entered one stable periodic orbit. Chaos behavior can be controlled and applied after the complex nonlinear characteristics of voltage regulated forward converter is researched. Meanwhile in order to study voltage regulated forward converter, mathematic model is researched deeply, the stability boundary is discussed. These research works guided the practical application of Engineering.

\section{ACKNOWLEDGMENT}

Project supported by the Scientific Research Projects (the general project of science and engineering)of Guangzhou City-belong University (Grant No. 1201420871, 1201420679) from Guangzhou City Bureau of Education. Project Also supported by the Twelfth FiveYear Educational Science Plan Project of Guangzhou City (Grant No. 2013A060, 2013A038).

\section{REFERENCES}

[1] G. H. Zhou, J. P. Xu, Y. Y. Jin, et al, "Stability analysis of $\mathrm{V}^{2}$ controlled buck converter operating in CCM and DCM," in Int Conf. Commun., Circuits. Syst., Chengdu, 2010, pp. 551-555.

[2] G. Yuan, S. Banerjee, E. Ott, et al., "Border-collision bifurcations in the buck converter," IEEE Trans Circuits Syst I, Fundam Theory Appl., vol. 45, 1998, pp. 707-716, DOI: 10.1109/81.703837.

[3] T. Szepesi, "Stabilizing the frequency of hysteretic current-mode DC/DC converters," IEEE Trans Power Electron, vol. 4, 1987, pp. 302-312, doi: 10.1109/TPEL.1987.4307865

[4] I. Daho, D. Giaouris, B. Zahawi, et al., "Stability analysis and bifurcation control of hysteresis current controlled ćuk converter using Filippov's method," PEMD 2008, pp. 381-385.

[5] D. Giaouris, S. Banerjee, and B. Zahawi, et al., "Stability Analysis of the Continuous-Conduction-Mode Buck Converter Via Filippov's Method," IEEE Trans Circuits Syst I, Reg Papers, vol 55, no. 4, pp. 1084-1096, doi: 10.1109/TCSI.2008.916443.

[6] R. I. Leine, D. H. VAN Campen, and B. L. VAN DE VRANDE, "Bifurcations in Nonlinear Discontinuous Systems," Nonlinear Dynam, vol. 23, 2000, pp. 105-164.

[7] C. K. Tse, "Flip bifurcation and chaos in three-state boost switching regulators," IEEE Trans. Circuits Syst. I Fundam. Theory Appl., Vol. 41, No. 1, Jan. 1994, pp. 16-23, doi $10.1109 / 81.260215$

[8] Erickson R W, Maksimovic D, Fundamentals of power electronics, New York: Springer, 2001, pp. 7.

[9] F. Xie, R. Yang, B. Zhang, "Bifurcation and border collision analysis of voltage-mode-controlled flyback converter based on total ampere-turns," IEEE Transactions on Circuits and Systems I: Regular Papers, vol. 58, no. 9, pp. 2269-2280.

[10] L. L. Xie, R. X. Gong, "Study of the mechanism of perioddoubling bifurcation in DCM flyback converter," Electronics and Application Conference and Exposition, 2014, pp. 1479-1485, DOI: 10.1109/PEAC.2014.7038083

[11] J. Wang, C. Bi, "Effect of leakage inductance on bifurcation and chaos in the voltage-fed forward converter," International Conference on Mechatronics and Automation, 2009, pp. 396-400, DOI: 10.1109/ICMA.2009.5245094.

[12] C. Bi, J. Wang, Z. Lan, K. Jia, T. Hu, "Investigation of bifurcation and chaos in forward converter," International Conference on Mechatronics and Automation, 2007, pp. 663-668, DOI: 10.1109/ICMA.2007.4303622. 